June - 2009

\title{
Questions of Culture in Distance Learning: A Research Review
}

\author{
Sedef Uzuner \\ State University of New York at Albany, USA
}

\begin{abstract}
This paper reviews past research that focused on questions of culture in distance learning. Of specific interest are the studies that examined the influence of culture on students' learning and engagement in asynchronous learning networks (ALNs). The purpose of this review is three-fold: to present the state of knowledge concerning the questions of culture in distance learning, to highlight important methodological issues that past research has left unresolved, and to provide practical insights into teaching culturally and linguistically diverse online communities of learners. For these purposes, 27 studies are examined and the findings are reported under the following two categories: What do studies focusing on questions of culture in distance learning tell us? What implications do they suggest for practice and future research? Also, the paper provides methodological insights for researchers who wish to investigate the cultural dimensions of distance learning in future studies.
\end{abstract}

Keywords: Asynchronous learning networks; culture; online learning; distance learning

\section{Introduction}

This paper will provide a definition of culture and use it to examine the research literature on distance learning. In particular, it will demonstrate how cultural factors interact with and influence students' learning and engagement in asynchronous learning networks (ALNs), networks for anytime and anywhere learning via computer communications technologies (Hiltz \& Goldman, 2005). The intent is to raise awareness about the cultural factors that may affect ALN learning and to provide guidance for practice and future research.

This paper views distance learning as a process that is sensitive to social, cultural, and contextual factors (Warschauer, 1998; Wegerif, 1998). Considering the cultural dimension as a crucial element in the effectiveness of ALNs, the paper supports and elaborates on the idea that successful ALN learning is not only dependent on optimal uses of available technologies, teachers' pedagogical-content knowledge, and students' motivation level, it is also dependent on the cultural (mental) representations learners and teachers bring to the learning situation. 


\section{Culture Defined}

Culture is a complex term to define precisely. As such, it has a long and complicated history. In most disciplines, the historical tendency has been to connect culture to nationality and ethnic origin. Grounded in the influential work of Hofstede (1980), the inclination has been to assume national groups as having the same patterns of thought, action, and values.

More recently, however, culture has been seen as an entity that transcends ethnic and national boundaries. Viewed from this perspective, culture encompasses "the patterns shaped by ethnicity, religion, socio-economic status, geography, profession, ideology, gender, and lifestyle" (Branch, 1993, p. 7). This more recent definition of culture embraces the idea that every person and human group is both cultural and multicultural.

For the purposes of this review, culture will be defined as acquired behaviors, perspectives, and values characteristic of a particular group or community.

\section{Overview and Problem Statement}

Traditional learning environments may become sites of struggle for teachers and learners when there is a collision of different cultures. More often than not, it is difficult for the teacher to accommodate each and every student's culture. Therefore, the students are expected "to step out of their own culture and temporarily enter into the culture of the instructor" (Moore, 2006, p. 1). Within this process, problems arise if the instructor's pedagogical values are not compatible with students' assumptions about how teaching should be done.

Basing teaching on one set of values, namely the dominant values, in culturally diverse settings usually results in what Gramsci (1971) called "cultural hegemony," a phenomenon that refers to the ways in which assumptions of a group/person achieve dominance and are viewed as commonsense understandings or interests that serve for all. Several scholars have remarked on the issue of cultural hegemony in traditional classrooms and have proposed theories advocating incorporation of multiple cultures in school curricula. Such theories include, but are not limited to, "culturally relevant pedagogy" (Ladson-Billings, 1995), "culturally responsive teaching" (Gay, 2000), "culturally sensitive instruction" (Boyer, 1993), and "multicultural instruction" (Saldana \& Waxman, 1996). These are valuable contributions that provide useful frameworks for understanding and dealing with issues of culture in traditional multicultural classrooms.

For the purposes of this review, the overarching questions become these: Does cultural hegemony also exist in distance education? Do conflicts resulting from cultural differences transfer from the traditional classroom to the distance learning environment? If so, how do teachers and students navigate different cultures of learning in these environments? These are the kinds of questions that need specific attention if our aim is to improve distance learning. 
In a highly comprehensive meta-analysis, Zhao, Lei, Yan, Lai, and Tan (2005) identified the factors impacting the effectiveness of distance education. Their analysis consisted of 423 empirical studies that compared face-to-face education to distance education. In the end, Zhao et al. (2005) concluded that "distance education in essence is still education [...] The factors found to have an impact on the effectiveness of distance education are also factors that would affect the effectiveness of face-to-face education" (p. 1865). In view of this finding, it is hypothesized that distance learning environments are by no means immune to the problems arising from cultural differences. In fact, these environments may even be more prone to cultural conflicts than traditional classrooms as instructors in these settings not only interact with students who have removed themselves from their native culture, but they also interact with students who remain "physically and socially within the different culture, a culture that is foreign to, and mostly unknown, to the teacher" (Moore, 2006, p. 1).

\section{Methodology}

The review was guided by the following question: What research evidence do we have on how culture influences students' distance learning experiences? For the purposes of this paper, students' distance learning experiences will be operationalized as their learning and engagement in ALNs.

The search for empirical articles focusing on the issues of culture in distance learning was conducted in three stages. First, significant electronic databases for education research (such as EBSCO, ERIC, Education Full Text, and PsycINFO) were searched. The following key words were used separately or in combination during this search: culture, online learning, distance education, cultural factors, multicultural, asynchronous learning networks, and e-learning. The second stage involved examination of the reference lists of the articles located in the electronic databases. Third, tables of contents of refereed open access electronic journals that are specifically concerned with distance education and ALNs were scrutinized for additional works. Since the focus was on data-based studies, conceptual articles that include discussions on how to promote cultural sensitivity in ALNs were discarded (e.g., Bates, 2001; Bentley, Tinney, \& Chia, 2005; Chen, Mashadi, Ang, \& Harkrider, 1999; Collis, 1999; Malbran \& Villar, 2001; McLoughlin, 1999; Smith \& Ayers, 2006; Wilson, 2001).

The search revealed 27 studies, two of which were dissertations. Based on methodology, these works were sorted into three categories: qualitative studies, quantitative studies, and mixed method studies, which used both qualitative and quantitative approaches to collect and analyze data.

The audience of this paper should keep in mind two important factors. First, the compilation of studies is influenced by the author's resource availability. Although every effort is made to make the literature presented here fully inclusive, works that are not abstracted in primary academic indexes (such as EBSCO, ERIC, Education Full Text, and PsycINFO) or are not peer reviewed open access electronic journals have been excluded. Nevertheless, despite having a small database, this review is important at this juncture in the field of distance education because it will 
allow designers, instructors, and researchers to understand the influences of culture in ALNs and to identify potential paths for future research.

Second, the author's distance learning and teaching experiences in the United States may have influenced this review. As such, some of the ideas may reflect a North American perspective. However, the cultural diversity reflected in the selected studies makes the recommendations in the remainder of this paper applicable to all culturally diverse distance learning environments.

\section{Findings}

The findings of the review will be reported under the following categories:

- What do studies focusing on questions of culture in distance learning tell us?

- What implications do they suggest for practice?

- What implications do they suggest for future research?

The review will also provide methodological insights for researchers who wish to investigate the cultural dimensions of distance learning in future studies.

\section{What do Studies Focusing on Questions of Culture in Distance Learning Tell Us?}

\section{Qualitative studies.}

Of the 27 studies reviewed, 12 were qualitative. Among these, some focused on particular national groups' ALN experiences. For example, Thompson and $\mathrm{Ku}$ (2005) explored seven Chinese graduate students' online learning experiences in an American university. One of the key findings of this study was that the participants were less critical and opinionated in online discussions than their US peers. Thompson and $\mathrm{Ku}$ attributed this finding to Hofstede's (1980) view that "Chinese culture is highly collective and feminine and tends to value group effort, harmony, affection, compassion and emotionality" (p. 43). The study also revealed the participants' frustration with the following issues in ALNs: not getting immediate feedback from the instructor, inability to understand specific cultural references in online discussions, and lack of face-to-face communication.

Tu (2001) and Zhao and McDougall (2000) also looked at Chinese online learners. Tu examined the impact of social context on Chinese graduate students' online interactions in ALNs in the U.S., and Zhao and McDougall explored Chinese graduate students' experiences and attitudes toward online learning in a Canadian university. Specifically, Tu's study emphasized the importance of social context in Chinese culture and showed how reliance on non-linguistic cues is tied to the way Chinese students interacted in ALNs. In Zhao and McDougall's study, cultural factors that were found to hinder six Chinese students' engagement in ALNs were their 
conservative, modest, and face-saving cultural traits and their unfamiliarity with the disciplinary cultures of education in Canada.

Another qualitative study that looked at a particular national group's ALN experiences was AlHarthi's (2005) study of six Arab students pursuing graduate degrees in the US. During in-depth interviews, these students expressed that they were at first scared and anxious about taking online courses because they equated online learning with independent learning, a finding reflecting Arab culture's high uncertainty avoidance (Hofstede, 1991). Students also reported that they intentionally participated less in online discussions than their American peers because they viewed eagerness to participate as "showing off or trying to appear smart" (p.9), a finding reflecting the importance of modesty in Arab culture. Other cultural factors that interfered with the students' successful ALN learning were found to be feelings of shame originating from Arab culture's social restrictions on the interactions between genders and communication difficulties with instructors arising from students' fear of confrontation with authority figures.

Rather than focusing on one particular nation, some studies investigated the distance learning experiences of various cultural groups. For example, Goodfellow, Lea, Gonzalez, and Mason (2001) focused on non-English speaking adults undertaking graduate level course work at a UKbased higher education institution. They found that these students' unfamiliarity with the linguistic and academic culture of the UK negatively impacted their success and academic performance. Shattuck (2005) studied Asian and Middle Eastern students taking distance education courses delivered by an American university, and Walker-Fernandez (1999) investigated non-American graduate students' experiences in an American distance education program while they were situated within their local cultures. These two studies found that cultural differences hinder students' communication and success in ALNs, causing them to experience feelings of isolation, alienation, and "dissonance out of conflict with the dominant educational culture" (Shattuck, 2005, p. 186).

Three studies (Morse, 2003; Gouthro, 2004; Biesenbach-Lucas, 2003) examined cross-cultural differences between two or more national/cultural groups. Morse (2003) compared the ALN experiences of students from the US, the UK, Australia, and New Zealand (the low context cultural group) to the experiences of students from Pakistan, the People's Republic of China, the Republic of China, Singapore, Sri Lanka, and Thailand (the high context cultural group). Morse found the low context group to be "outwardly oriented" in their computer-mediated communications $(\mathrm{CMC})$, meaning that these students valued the time afforded by CMC to reflect on other people's opinions. On the other hand, he found the high context participants to be more "inwardly oriented," meaning these students valued the time afforded by CMC to think more about their own contributions. This study also revealed that students from high context cultures viewed the lack of face-to-face contact with faculty and peers as a challenge to their ability to learn and form social relationships, whereas low context participants did not believe that the lack of face-to-face contact impacted their learning abilities positively or negatively.

Gouthro (2004) investigated Jamaican and Canadian women's distance learning experiences in a graduate level adult education program. Although findings of this study were interpreted mainly 
from a gender perspective, a significant cultural issue emerged: both groups' cultural expectations regarding women's roles in the home did limit their learning, participation, and engagement in ALNs. In light of this finding, Gouthro wrote, "distance educators teaching in higher education need to be aware of the complex circumstances in which women learners come to participate, and be attentive to power issues around gender and culture in the classroom and in the homeplace" (p. 459).

Biesenbach-Lucas (2003) examined the attitudes and behaviors of American and non-American students, who were mainly from Asian cultures, toward asynchronous discussions that were incorporated into two graduate level teacher training courses at an American university. The results revealed that both groups perceived online discussions to be beneficial for social interaction and learning. These discussions were especially found to provide non-American students with spaces where they could "explore issues at their own pace, examine topics from various angles until they felt they had reached an understanding of material not presented in their native language" (p. 31). An interesting finding that emerged from this study was that both American and non-American students avoided expressing disagreement with others and their posts "did not include the kind of reflection that showed critical evaluation and synthesis of information" (p.33). Biesenbach-Lucas made the point that perhaps two factors were at play in non-American students' avoidance of disagreement: they may consider challenging and criticizing other's ideas culturally inappropriate, and/or they may "not know how to express disagreement appropriately in English" (p. 37).

Of the studies focusing on culture Fang's (2007) study was unique because it investigated the impact of multiple levels of cultures (such as national culture, ethnic culture, and cyber culture) on students' ALN experiences. Twenty Singaporean Chinese engineering students were the focus of this study. The purpose was to understand how different levels of culture influenced what these students perceived as useful, enjoyable, and effective in a predominantly online program. The results, based on individual and group interviews, were as follows: Influenced by their national culture, which values achievement and success, the students cared less for fun and exciting activities and valued tasks that led to achievement in learning. Influenced by their ethnic (Chinese) culture, which stresses learning from an authority figure, the students preferred teacher feedback to peer feedback. Lastly, influenced by their cyber culture, the students appreciated the convenience, flexibility, and social benefits of ALNs.

The last study in this category was Rogers, Graham, and Mayes' (2007) study, which looked at the issue of culture in ALNs from the perspective of instructional designers. Through interviews with 12 professionals involved in the design of online courses delivered cross-culturally, Rogers et al. (2007) found that instructional designers' or instructors' awareness of the potential differences between cultures does not necessarily mean this knowledge is integrated into the design of online courses. 


\section{Quantitative studies.}

Of the 27 studies reviewed, seven were quantitative in nature, using survey methodology. Below, these studies and their key findings will be discussed briefly.

Smith, Coldwell, Smith, and Murphy's (2005) survey research explored the similarities and differences between Australian and Chinese undergraduate students' engagement in online discussions. The findings indicated that compared to their Australian peers, Chinese students were less engaged in critical thinking in their posts. Smith et al. (2005) noted that "the lower number of intellectual postings may not indicate that these students had less to say, but that they were constrained in saying it, possibly further compounded by the fact that the discussion was in English" (p. 131). This study also found that Chinese students displayed a higher level of anxiety in ALNs than their Australian counterparts over issues such as course requirements and assessment, and they showed a strong need for transparency in course structure. This finding echoed another survey report by Smith and Smith (1999), which indicated that Chinese heritage students tend to display more anxiety than Australian students in terms of their general approaches to learning.

Anakwe and Christensen (1999) investigated whether differences arising from individualistic and collectivistic cultural orientations impacted 424 undergraduate and graduate students' perceptions of distance learning in two American universities. The results showed distance learning to be more compatible with individualists' motives and ways of interacting. A similar study was also conducted by Tapanes, Smith, and White (2009). Based on survey data obtained from 40 online students from two American universities, this study found students from collectivistic cultures to be less motivated to participate in ALNs than those from individualistic cultures.

In another survey-based research project, Smith and Smith (2000) studied the differences among Malaysian-Chinese, Singaporean, and Hong Kong first year undergraduate students taking distance courses from an Australian university. Significant differences were found among these three groups. For example, Malaysian-Chinese and Singaporean students were found to be equally dependent on structured instruction, but both groups differed in terms of their learning orientations. While Singaporean students demonstrated deep level learning, Malaysian-Chinese students showed a tendency for more surface and less organized forms of learning in ALNs. Compared to these two groups, Hong Kong students demonstrated less dependence on structure, but they showed a higher fear of failure. As was the case with Singaporean students, Hong Kong students demonstrated deep level learning. Based on these findings, Smith and Smith (2000) concluded that culture does impact various national groups' learning behavior in ALNs.

Lim (2004) used surveys to compare 236 undergraduate and graduate students' online learning motivation by country. Students enrolled in online courses at four Korean universities $(N=95)$ and an American university $(N=141)$ were the participants. The findings were that regardless of the country affiliation, all students considered course relevancy (belief that a particular course matches a student's needs) as the most important motivational factor in their online learning. The differences between the two groups were that while American students indicated they "prefer 
voicing personal opinions during class, enjoy learning and enroll in classes to obtain a sense of belonging," Korean students expressed their tendency to "avoid voicing their opinions and keep passive and quiet during class as they are influenced by the authoritarian classroom context of Asian culture" (169-170). These findings supported Lim's contention that cultural orientation influences national groups' learning motivation in ALNs.

Hannon and D'Netto (2007) surveyed Australian and non-Australian/international students to find out how linguistic and cultural backgrounds impacted their engagement in ALNs. The students surveyed were undergraduate and graduate students $(N=241)$ taking business classes at a large Australian university. The findings revealed that international students differed from Australian students in terms of their perceptions of and satisfaction with their ALN experiences. Specifically, international students experienced more challenges with technological aspects of online learning and more isolation in ALNs than their Australian peers.

\section{Mixed method studies.}

Of the 27 studies reviewed, eight employed mixed-methods, using both qualitative and quantitative approaches to collect and analyze data. The key findings of these studies will be discussed below.

Through surveys and focus group interviews, $\mathrm{Ku}$ and Lohr (2003) studied 23 graduate students' (18 American, 2 Chinese, and 3 Taiwanese) perceptions and attitudes towards their first ALN experiences in the U.S. Some of these students indicated that they felt uncomfortable with the nonlinear nature of their online course and its emphasis on peer feedback. This finding was attributed to the uncertainty avoidance dimension of Asian culture as described by Hoftede (1991). The study also found that Chinese and Taiwanese students "liked the idea of building an online community among peers and instructors" (p. 100), a finding reflecting the collectivistfemininity attributes of their culture.

Using surveys and focus group interviews, Gunawardena, Nolla, Wilson, Lopez-Islas, RamirezAngel, and Rosa (2001) examined Mexican and American students' perceptions of online group process and development. Fifty American and 50 Mexican students who were enrolled in distance education programs in their respective local contexts participated in this study. Framed within theories of group development, diversity, and culture, this cross-cultural study found strong evidence showing the influence of students' national culture on their online learning behaviors. For example, compared to their American peers, Mexican students showed higher tendencies for affection, compassion, and emotion in online group processes, a finding that reflects the importance of care and affection in Mexican culture (Hosftede, 1980).

Selinger (2004) investigated the implementation of a global e-learning program, which is based on Western learning theories, in countries such as Denmark, France, Germany, Hungary, Italy, Poland, Spain, Sweden, South Africa, United Arab Emirates and the UK. Data from surveys and interviews with 300 students and 100 instructors from these countries provided support for Edmundson's (2009) claim that "e-learning courses are cultural artifacts, embedded with the 
cultural values, preferences, characteristics, and nuances of the culture that designed them, and inherently creating challenges for learners from other cultures" (p. 42). Emphasizing the importance of cultural context in learning and thinking, Selinger's study highlighted the importance of training local instructors so they can make a course that is developed in another country (predominantly in the US) culturally and pedagogically relevant to students in their local contexts.

Wang (2007) conducted a cross-cultural study to investigate the differences among Chinese, Korean, and American students in terms of their motivation to participate in online discussions, perceptions of online team work, and comfort level in approaching their online instructors. Participants in this study were students from universities across the US, China, and South Korea, and data were drawn predominantly from online surveys. The findings revealed that students' cultural identity has a significant impact on their participation in and perceptions of ALNs. Specifically, course requirement was found to be the major factor behind Korean and Chinese students' participation in online discussions and activities. American students, on the other hand, indicated that they participated in online discussions because they enjoyed connecting with their peers. All three cultural groups preferred asynchronous discussions to synchronous ones. Wang (2007) attributed Korean and Chinese students' preference for asynchronous communication to an Asian cultural trait, "think more, talk less, and think it through before speaking" (p. 303). Although all three cultural groups found individual work boring and challenging, mixed results were found regarding their perceptions of online team work. Among the three groups, Korean students were found to be the least comfortable with online collaborative work. The study also showed that American students tended to communicate more with their instructors because they perceived them as equals, whereas Korean and Chinese students reported low levels of comfort in approaching their instructors. Wang (2007) attributed this finding to Asian culture's embodiment of power distance.

Liang and McQueen (2000) examined the impact of e-mail interaction on the learning outcomes of 18 culturally diverse adult learners from China, Fiji, Hong Kong, Korea, New Zealand, the Philippines, South Africa, Taiwan, and the US. Data from questionnaires, observations, and interviews revealed that Western students were more open to the idea of learning from peers online and perceived peer interaction to be beneficial intellectually, affectively, and interpersonally. On the other hand, Asian students valued teacher input more than peer input and perceived online peer-to-peer interaction to be beneficial only when it assisted their learning.

Kim and Bonk's (2002) cross-cultural study examined the differences in Finnish, Korean, and American undergraduate pre-service teachers' online collaborative behaviors. Qualitative and quantitative content analysis of three asynchronous web-based conferences revealed that each group exhibited distinct behaviors in ALNs. For example, both Finnish and American students were task-oriented, but they differed in the way they participated in asynchronous discussions. In their communications, Finnish students were concerned with theory and demonstrated a higher level of reflection, while American students were concerned less with theory and more with practice. Korean students, on the other hand, were contextually-driven and demonstrated the highest level of social interaction behaviors among the groups studied. 
Chen, Hsu, and Caropreso (2006) investigated the influence of culture on 15 graduate students' (10 American and 5 Taiwanese) social learning behaviors during online collaboration. Qualitative and quantitative content analysis of students' online messages in discussion forums were supplemented with data from an attitude survey. The results revealed culture-based differences in both groups' online collaboration and communication patterns. For example, American students preferred individualistic division of labor in collaborative assignments and possessed communication patterns that were short and content-driven. Taiwanese students, on the other hand, displayed group-based behaviors and were more inclined to produce long messages that included emotional expressions and numerous references to their personal contexts. More importantly, perhaps, this research indicated how cultural differences at times create tensions between culturally diverse student groups while working together online. For example, Taiwanese students interpreted American students' fast-paced responses as a sign of aggressiveness, and American students viewed Taiwanese students' delayed participation in discussions as a sign of passivity and weakness.

The final study in this category is Bing and Ai-Ping's (2008) study, which examined the influence of national culture on learners' asynchronous interactions in two distance education institutions, one in China and the other in Malaysia. Using qualitative and quantitative content analysis, the researchers divided students' interactions into five categories (social, procedural, expository, explanatory, and cognitive) and explained group differences by using Hofstede's (1991) cultural dimensions. The results revealed that Malaysian learners had a higher degree of individualism and lower degree of masculinity and power distance compared to their Chinese peers. Consistent with other study findings (Smith et al., 2005; Smith \& Smith, 1999) Chinese learners were found to display a high degree of uncertainty avoidance. As Bing and Ai-Ping wrote, "they wanted to be certain of the exact scope of assessments and preferred a more structured way of learning" (p. 333). One common feature in both groups' interactions was that the cognitive dimension, which is associated with higher order thinking, was the least dominant dimension.

In sum, despite the flaws inherent in their design or execution (methodological weaknesses of these studies will be described in a later section of this review), the studies summarized above provide a strong research base on the cultural dimensions of learning in ALNs.

\section{What Implications do these Studies Suggest for Practice?}

Some papers reviewed above provided explicit recommendations for practice, while others did not. Nonetheless, a broad yet incomplete list of recommendations emerged from this review. These recommendations are described below.

1. Some studies (e.g., Al-Harthi, 2005; Bing \& Ai-Ping, 2008; Smith et al., 2005; Smith \& Smith, 1999; Wang, 2007) showed that learners from strong uncertainty avoidance cultures are threatened by learning situations that are unstructured and unclear. They expect formal rules to guide their behavior. For example, Smith and Smith (1999) found that Chinese students display a strong need for "structured programs of instruction where 
the logic of that structure is transparent to the student" (p. 77). In a similar vein, when discussing the factors impacting Korean and Chinese students' participation in ALNs, Wang wrote: "the 'rules' for online participation were unclear. Both Chinese and Korean students, who rarely spoke in traditional classrooms, felt lost when they were expected to speak online. They wondered if there were any rules and rituals for them to follow" ( $\mathrm{p}$. 304). To alleviate such student anxieties, online instructors should make their course structure transparent by setting clear expectations for participation, assignments, learning activities, team work, grading, submission dates, and assessment.

2. Influenced by cultural traditions that discourage the "nail that sticks up," some students tend to show passive presence in ALNs. For example, Taiwanese participants in Chen, Hsu, and Caropreso's (2006) study “appeared to be passive toward interacting with group members, while U.S. students appeared actively engaged and energetic” (p. 23). Similarly, Zhao and McDougall (2008) found that some of the Chinese learners participating in their study "hesitated to ask questions and some even gave up on a discussion or contributed fewer messages when their opinions conflicted with those of other participants" (p. 72). Last but not least, Liang and McQueen's (2000) study demonstrated that Asian students "tend to hold back their thoughts when they perceive the teacher or majority of the learning peers will not favorably receive messages that are contrary to what they want to hear" (p. 28). These findings indicate that in distance learning contexts (such as the North American distance learning contexts) where active participation in discussions is highly valued, instructors should make specific efforts to promote critique and divergence and encourage students to create a safe space where opinions, experiences, beliefs, and knowledge can be shared.

3. Morse's (2003) and Hannon and D'Netto's study (2007) drew attention to the fact that the skills and experiences students bring to the distance learning environment are highly influenced by their cultural backgrounds. Therefore, instructors should be cognizant of variations in students' experience and learning styles and at the outset of the course remind learners that learning activities in ALNs may be different from what the learners are accustomed to. It is also equally important that instructors model the target behavior or learning outcome expected from the students. For example, in distance education environments such as the American one, critical reflection is highly valued. The instructors in these contexts should not assume that all students are familiar with reflection processes. In fact, as Biesenbach-Lucas's (2003) and Thompson and Ku's (2005) studies show, challenging and criticizing others' ideas may not be considered culturally appropriate in some cultural groups.

4. Tu (2001), Kim and Bonk (2002), Morse (2003), and Ku and Lohr (2003) showed that social presence is the key for the success of students from context dependent cultures. To improve the likelihood of such learners' success, Thompson and $\mathrm{Ku}(2005, \mathrm{p}$. 45) made the following recommendations for online instructors:

a. Get to know the students. Encourage students to send their pictures and post their background information and interests online. 
b. Encourage students to communicate with each other both online and offline. For example, exchange phone numbers, meet in person, use email, fax, the discussion board, and the chat room.

c. Encourage face-to-face interactions or meetings with classmates and instructors when possible.

5. Anakwe and Christensen (1999) found that "relationship building is foremost" for students from collectivist cultures (p. 240). This finding has significant implications for online instructors who emphasize collaborative work in their courses. One implication is that online instructors should allow sufficient time to develop relationships prior to engaging learners in collaborative activities (Liang \& McQueen, 2000). In addition, they should allow learners to work in small groups, encourage diversity in those groups (Thompson \& Ku, 2005; Wang \& Reeves, 2007), and always monitor the nature and scope of team work (Wang, 2007).

6. Wang's (2007) and Al-Harthi's (2005) studies illustrated how students from large power index cultures (Hofstede, 1991) are intimidated by the thought of approaching their instructors. In line with this finding, some of the authors whose works are included in this review recommended that online instructors pay attention to power issues, position themselves as equal to students (Wang, 2007), and be available for consultation and guidance (Smith et al, 2005).

7. When knowledge is embedded in the dominant culture, learners who are foreign to that culture lose their motivation to understand it. The frustration felt by a Chinese student in Thompson and Ku's (2005) study as a result of being unable to understand the cultural references used by her American peers in online discussions is a case in point. To avoid situations like this one, online instructors should provide background information when specific cultural references are used in ALNs.

8. Liang and McQueen (2000), Fang (2007), and Thompson and Ku (2005) found that students from Asian cultures, who see instructors as authority figures, value teacher feedback more than peer feedback and get frustrated when they do not see teacher presence in ALNs. For example, Hong, a Chinese student from Thompson and Ku's (2005) study stated:

It is like students are exploring an unknown territory in a forest. The instructor eventually comes out and leads us to the right path. Because we think the teacher is an authority figure, we want to know what his thoughts are instead of discussing among ourselves blindly. (p. 42)

These findings suggest that online instructors should integrate feedback into the peer review processes and increase the amount of individual teacher feedback students receive.

9. Last but not least, Shattuck (2005) found that "constructivist-based pedagogy couched in the highly interactive communication world can be a lonely place for an international online learner whose cultural experiences are different than the dominant educational cultures" (p. 186). This finding logically leads us to conclude that online instructors 
should not simply implement "best practices," which are born out of dominant educational cultures, in their courses without knowing the needs of their learners. As Selinger (2004) noted, instructors' roles and decisions are pivotal in making ALN learning successful for students. Therefore, to ensure that these decisions improve culturally diverse groups' ALN experiences, online instructors need to effectively conduct needs assessments and engage in an ongoing process of re-constructing their teaching approaches based on the results of these assessments.

\section{What Implications does this Review Suggest for Future Research?}

Although research focusing on the impact of culture on ALN learning has increased in the past decade, there are several gaps in the literature.

First, there is a dearth of studies looking at the questions of culture in ALNs among domestic diversity cultures. For example, what are the experiences of African American, Latino-American, and/or Asian-American students taking distance learning courses in the U.S.? Empirical attention to the interaction between learners from dominant and diversity cultures would reveal useful insights in understanding the complexity of student learning in ALNs. Studies of this sort will enrich our knowledge base as to how different populations of students representing the dominant and diversity cultures both resemble and contrast with one another in distance learning environments.

Second, the vast majority of research tends to surround Asian learners and their ALN experiences. More studies looking at the influences of culture on students from other cultures, such as German, French, Hungarian, Polish, Turkish, Greek, Iranian, Indian, etc, are needed. Research into these, so far under-represented, groups will provide instructors with important insights.

Lastly, in most cultural studies included in this review, there was a tendency to lump students into one category without paying attention to their individual differences. This problem is also echoed by Gunawardena et al. (2001) who wrote the following:

Individual differences in cultural groups need to be accounted for so that we do not subscribe to the fallacy of homogeneity (that terms such as "American" connote international sameness), or the fallacy of monolithic identity (the assumption that individuals in groups have no differential identities) (p. 117).

In future studies, attention to this distinction would likely prove fruitful in understanding the complexity of ALN learning as it will prevent researchers from generating fixed conceptualizations of various groups' cultural characteristics.

\section{Methodological Insights}

The papers discussed in this review provide useful insights into the cultural dimensions of student learning in ALNs. Overall, their strength lies in their exploratory nature and focus on pragmatic considerations. However, a major weakness of these studies is that most of them did not follow 
rigorous designs or analyses. A discussion of the theoretical and methodological weaknesses of these studies follows below.

The review herein supports Patton's (2002) contention that “there are no perfect research designs. There are always trade-offs" (p.223). Therefore, the goal in this section is not to isolate particular studies, point out flaws in their design and conduct, or undermine their conclusions. Rather, the intent of the following discussion is to provide methodological insights for researchers who plan future studies on cultural factors impacting student learning in ALNs.

Let us start with qualitative studies. While such studies enriched our knowledge of the cultural issues impacting ALNs, most fell short of meeting the conventional standards of qualitative research designs. For example, few had a solid foundation in theories. The ones that did make use of theories, however, relied on the same, existing theoretical models (such as Edward Hall's and Geert Hoftede's cultural constructs) to explain students' culture-bounded behaviors in ALNs. In future qualitative studies, researchers should provide theoretical underpinnings for their work, and in so doing they should break theoretical boundaries and engage in creative application of concepts from different disciplines.

Anfara, Brown, and Mangione (2002) recommend that qualitative researchers "account for and disclose all aspects of the research process" (p. 28). They highlight analytic openness as key to conducting methodologically sound qualitative research. When we look at the qualitative studies reviewed above, however, we find that only a handful of researchers provided detailed explanations of the inner workings of their research process. For example, in most papers, no mention was made of how themes and categories were developed, what verification processes were used to confirm validity, or how triangulation was achieved. Moreover, almost all of the qualitative studies relied on interviews, yet none provided the readers with information about what questions were asked in the interview protocols. Lastly, none of the qualitative studies included in this review addressed researcher bias, and only a few provided methodological justifications regarding the sampling approaches used. It is important that researchers attend to these issues and make the inner workings of the overall research process public in future qualitative reports.

In addition to the qualitative works, some of the studies included in this review employed quantitative or mixed method (qualitative and quantitative) approaches. Studies of this type mainly relied on survey methodology, but only a few succeeded in following a rigorous survey research design. Overall, eight weaknesses were identifiable: 1) inadequate sampling size that compromised generalization to larger populations; 2) minimal description of the sampling approaches, the defining boundaries of the population, and the criteria of inclusion and exclusion of the sampling frame; 3) lack of hypotheses and/or definitions of the independent and dependent variables; 4) minimal or no information about the survey instrument, pre-testing, and piloting; 5) minimal or no information about the initial size of the sample and the final percentage that responded to the surveys; 6) inadequate descriptions of data collection and analysis procedures; 7) inadequate coverage of the literature; and 8) over-reliance on cross-sectional surveys. 


\section{Discussion and Conclusions}

Empirical works reviewed in this paper provide useful insights into the influences of culture on students' ALN experiences. Despite their varying contexts and focus, it is possible to identify common threads running through them. Notable in particular among these studies is an emphasis on the idea that culture is inseparable from distance learning and teaching. Researchers express broad agreement that the diverse cultural assumptions students bring to ALNs concerning how teaching and learning should be done bring about conflicts, disagreements, and frustrations. Not surprisingly, the issues dealt with in these studies resemble those faced by traditional classroom teachers who teach culturally and linguistically diverse students. This validates Zhao et al.'s (2005) conclusion that "distance education in essence is still education [...] The factors found to have an impact on the effectiveness of distance education are also factors that would affect the effectiveness of face-to-face education" (p. 1865).

Another point that emerges from these studies is their emphasis on practical issues. The studies support a multicultural perspective on the aims and conduct of distance education and identify the ways in which teaching in ALNs can best be done to enhance several different cultural groups' learning. Specific recommendations that emerged from these studies were described earlier. On such practical matters, it is fair to argue that those recommendations would be good not only for international or multicultural students but also for everyone engaged in distance learning. Recognizing this fact leads us to conclude that good practices for culturally diverse online learning environments are good practices for others where teachers and students are operating within the same culture and space.

Finally, the reviewed studies point to the need to recognize the diversity within online communities of learners. Researchers express broad agreement that online instructors should be sensitive to cultural issues, become aware of the variations in students' learning strategies, and avoid adopting the "one size fits all" approach when viewing the process of learning for their students in ALNs. It can be argued that within the process of becoming aware of the needs of students from other cultures, online instructors can also become aware of the diverse needs of students from their own culture. This heightened sensitivity will benefit students in general.

Clearly, the limited number of studies $(N=27)$ located in available databases and online open access journals may be indicative of the fact that cultural dimensions of ALNs are a relatively new field of study, one in which important insights have yet to be discovered. Continued research that is grounded in sound methodology is certainly needed to improve our understanding of it.

\section{Acknowledgements}

The author would like to thank Jason Smith, Dr. Peter Shea from SUNY Albany, and two anonymous reviewers for their insightful comments, and she is especially grateful to Terry Anderson for his invaluable editorial guidance. 


\section{References}

Al-Harthi, A. S. (2005). Distance higher education experiences of Arab Gulf students in the United States: A cultural perspective. International Review of Research in Open and Distance Learning, 6(3), 1-14.

Anakwe, U. P., \& Christensen, E. W. (1999). Distance learning and cultural diversity: Potential users' perspective. The International Journal of Organizational Analysis, 7(3), 224-243.

Anfara, V. A., Brown, K. M., \& Mangione, T. L. (2002). Qualitative analysis on stage: Making the research process more public. Educational Researcher, 31(7), 28-38.

Bates, T. (2001). International distance education: Cultural and ethical issues. Distance Education, 22(1), 122-136.

Bentley, J. P. H., Tinney, M. V., \& Chia, B. H. (2005). Intercultural internet-based learning: Know your audience and what it values. Educational Technology Research \& Development, 53(2), 117-127.

Biesenbach-Lucas, S. (2003). Asynchronous discussion groups in teacher training classes: Perceptions of native and non-native students. Journal of Asynchronous Learning Networks, 7(3), 24-46.

Bing, W., \& Ai-Ping, T. (2008). The influence of national culture toward learners' interaction in the online learning environment: A comparative analysis of Shanghai TV University (China) and Wawasan Open University (Malaysia). The Quarterly Review of Distance Education, 9(3), 327-339.

Boyer, J. B. (1993). Culturally sensitive instruction: An essential component of education for diversity. Catalyst for Change, 22, 5-8.

Branch, R. M. (1997). Educational technology frameworks that facilitate culturally pluralistic instruction. Educational Technology, 37, 38-41.

Chen, S., Hsu, C., \& Caropreso, E. J. (2006). Cross-cultural collaborative online learning: When the West meets the East. International Journal of Technology in Teaching and Learning, 2(1), 17-35.

Chen, A., Mashhadi, A., Ang, D., \& Harkrider, N. (1999). Cultural issues in the design of technology-enhanced learning systems. British Journal of Educational Technology, $30(3), 217-230$.

Collis, B. (1999). Designing for differences: cultural issues in the design of WWW-based coursesupport sites. British Journal of Educational Technology, 30(3), 201-215. 
Edmundson, A. (2009). Culturally accessible e-learning: An overdue global business imperative. Retrieved May 15, 2009, from http://www.astd.org/LC/2009/0509_edmundson.htm

Fang, L. (2007). Perceiving the useful, enjoyable, and effective: A case study of the e-learning experience of tertiary students in Singapore. Educational Media International, 44(3), 237-253.

Gay, G. (2000). Culturally responsive teaching: Theory, research, \& practice. New York: Teachers College Press.

Goodfellow, R., Lea, M., Gonzales, F., \& Mason, R. (2001). Opportunity and e-quality: Intercultural and linguistic issues in global online learning. Distance Education, 22(1) 6584.

Gouthro, P. A. (2004). Assessing power issues in Canadian and Jamaican women's experiences in learning via distance in higher education. Teaching in Higher Education, 9(4), 449461.

Gramsci, A. (1971). Selections from the prison notebooks. London: Lawrence and Wishart.

Gunawardena, C. N., Nolla, A. C., Wilson, P. L., Lopez-Islas, J. R., Ramirez-Angel, N., \& Megchun-Alpizar, R. M. (2001). A cross-cultural study of group process and development in online conferences. Distance Education, 22(1), 85-121.

Hannon, J., \& D’Neto, B. (2007). Cultural diversity online: Student engagement with learning technologies. International Journal of Educational Management, 21(5), 418-432.

Hiltz, S. R., \& Goldman, R. (2005). What are asynchronous learning networks? In S. R. Hiltz and R. Goldman (Eds), Learning together online: Research on asynchronous learning networks (pp. 3-18). Mahwah, NJ: Lawrence Erlbaum.

Hofstede, G. (1991). Cultures and organizations: Software of the mind. London: McGraw-Hill.

Hofstede, G. (1980). Culture's consequences: International differences in work-related values. Beverly Hills, CA: Sage Publications.

Kim, K. J., \& Bonk, C. J. (2002). Cross-cultural comparisons of online collaboration among preservice teachers in Finland, Korea, and the United States. Journal of Computer-Mediated Communication, 8(1).

Ku, H. Y., \& Lohr, L. L. (2003). A case study of Chinese students' attitudes toward their first online learning experience. Educational Technology Research and Development, 51(3), 95-102. 
Ladson-Billings, G. (1995). Toward a theory of culturally relevant pedagogy. American Educational Research Journal, 32(3), 465-491.

Liang, A., \& McQueen, R., J. (2000). Computer assisted adult interactive learning in a multicultural environment. Adult Learning, 11(1), 26-29.

Lim, D. H. (2004). Cross cultural differences in online learning motivation. Educational Media International, 41(2), 163-175.

Malbran, M. C., \& Villar, C. M. (2001). Incorporating cultural relevance into online courses: The case of VirtualMente. Distance Education, 22(1), 168-174.

McLoughlin, C. (1999). Culturally responsive technology use: Developing an online community of learners. British Journal of Educational Technology, 30(3), 231-243.

Moore, M. (2006). Editorial. The American Journal of Distance Education. 20(1), 1-5.

Morse, K. (2003). Does one size fit all? Exploring asynchronous learning in a multicultural environment. Journal of Asynchronous Learning Networks, 7(1), 37-55.

Patton, M. Q. (2002). Qualitative research and evaluation methods. Thousand Oaks, CA: Sage Publications.

Rogers, P. C., Graham, C. R., \& Mayes, C. T. (2007). Cultural competence and instructional design: Exploration research into the delivery of online instruction cross-culturally. Educational Technology Research and Development, 55(2), 197-217.

Saldana, D.C., \& Waxman, H. (1996). The integration of multicultural education in urban middle level schools. Current Issues in Middle Level Education, 5, 9-29.

Selinger, M. (2004). Cultural and pedagogical implications of a global e-learning programme. Cambridge Journal of Education, 34(2), 223-239.

Shattuck, K. (2005). Cultures meeting cultures in online distance education: Perceptions of international adult learners of the impact of culture when taking online distance education courses designed and delivered by an American University. Unpublished doctoral dissertation, The Pennsylvania State University, University Park.

Smith, D. R., \& Ayers, D. F. (2006). Culturally responsive pedagogy and online learning: Implications for the globalized community college. Community College Journal of Research and Practice, 30, 401-415.

Smith, P.J., Coldwell, J., Smith, S. N., \& Murphy, K. L. (2005). Learning through computer- 
mediated communication: A comparison of Australian and Chinese heritage students. Innovations in Education and Teaching International, 42(2), 123-134.

Smith, S. N., \& Smith, P. J. (2000). Implications for distance education in the study approaches of different Chinese national groups. The Journal of Distance Education, 15(2), 71-84.

Smith, P. J., \& Smith, S. N. (1999). Differences between Chinese and Australian students: Some implications for distance educators. Distance Education, 20(1), 64-80.

Tapanes, M. A., Smith, G. G., \& White, J. A. (2009). Cultural diversity in online learning: A study of the perceived effects of dissonance in levels of individualism/collectivism and tolerance of ambiguity. The Internet and Higher Education, 12, 26-34.

Thompson, L., \& Ku, H. (2005). Chinese graduate students' experiences and attitudes toward online learning. Educational Media International, 42(1), 33-47.

Tu, C. (2001). How Chinese perceive social presence: An examination of interaction in online learning environment. Educational Media International, 38(1), 45-60.

Walker-Fernandez, S. E. (1999). Toward understanding the study experiences of culturally sensitive graduate students in American distance education programs. Unpublished doctoral dissertation, Florida International University, Miami.

Wang, M. (2007) Designing online courses that effectively engage learners from diverse cultural backgrounds. British Journal of Educational Technology, 38(2), 294-311.

Warschauer, M. (1998). Online learning in sociocultural context. Anthropology \& Education Quarterly, 29(1), 68-88.

Wegerif, R. (1998). The social dimension of asynchronous learning networks. Journal of Asynchronous Learning Networks, 2(1), 34-49.

Wilson, M. S. (2001). Cultural considerations in online instruction and learning. Distance Education, 22(1), 52-64.

Zhao, N., \& McDougall, D. (2008). Cultural influences on Chinese students' asynchronous online learning in a Canadian university. Journal of Distance Education, 22(2), 59-80.

Zhao, Y., Lei, J., Yan, B., Lai, C., \& Tan, H. S. (2005) What makes the difference? A practical analysis of research on the effectiveness of distance education. Teachers College Record, 107(8), 1836-1884.

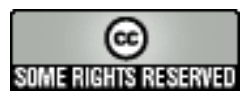

